\title{
GENEALOGI KAJIAN PASCAKOLONIALISME DALAM KHAZANAH KRITIK SASTRA ARAB
}

\author{
Mirza Syauqi Futaqi
}

futaqimirza@gmail.com

Fakultas Adab dan Ilmu Budaya, UIN Sunan Kalijaga

Sleman, Yogyakarta, Indonesia

\begin{abstract}
This study is a comparative literature study that seeks to investigate postcolonialism study in the Arabic Literary Criticism from the early postcolonialism study to the current postcolonial study. This study uses American comparative literature theory, the diachronic approach, and historical methods. The results of this study are that postcolonialism entered into the Arabic Literary Criticism through postcolonial theory book that was translated to Arabic language, students who studied in America or Europe and then taught at universities in the Arabic world, and also the internet. In addition, the attitude of the Arabs towards postcolonialism study in the Arabic Literary Criticism is still limited as consumers and not theorists.
\end{abstract}

Keywords: Postcolonialism Study, the Arabic Literary Criticism, American comparative literature theory.

\section{PENDAHULUAN}

Kajian pascakolonialisme merupakan kajian yang relatif lebih mutakhir dibanding kajian lainnya seperti kajian antropologi, psikologi, atau sosiologi. Hal ini disebabkan karena kajian pascakolonialisme merupakan respon terhadap kolonialisme yang dilakukan bangsa Barat terhadap bangsa Timur. Secara spesifik, di dalam kajian sastra dan filsafat, kajian pascakolonialisme merupakan babak baru dari pascamodernisme. Hal ini berangkat dari fakta bahwa kajian pascakolonialisme merupakan kajian yang relatif baru yang memanfaatkan sejumlah konsep yang ada di dalam pascamodernisme. Meski begitu, kajian pascakolonialisme adalah kajian yang berbeda dengan kajian pascamodernisme. Jika pascamodernisme adalah dekonstruksi atas modernisme maka pascakolonialisme merupakan dekonstruksi atas struktur kolonialisme sebagai salah satu akibat dari modernisme.

Secara sederhana dapat disimpulkan bahwa pascakolonialisme adalah sebuah kajian yang mencoba menginvestigasi dampakdampak negatif kolonialisme. Sebenarnya kajian pascakolonialisme adalah kajian khusus tentang negara-negara yang pernah dijajah seperti Indonesia, Aljazair, Mesir dsb. Hal ini tentu berbeda dengan kajian pascamodernisme yang merupakan kajian tentang segala bentuk narasi yang menjajah, menindas dan memarginalkan yang cakupan jauh lebih luas. Namun, karena dahulu, menurut Edward Said, pada tahun 1914 bangsa barat telah menguasai $85 \%$ daerah di bumi, kajian pascakolonialisme dianggap telah berpengaruh secara global (Ratna, 2010, hal. 235).

Salah satu bangsa yang terpengaruh kajian pascakolonialisme adalah bangsa Arab, khususnya di dalam bidang kritik sastra dan budaya. Ketertarikan mereka terhadap kajian pascakolonialisme terjadi karena masifnya dampak kolonialisme terhadap bangsa mereka. Misalnya, meski Algeria menetapkan bahasa Arab sebagai bahasa resminya. Namun, praktiknya, bahasa Lingua Franca mereka bukan bahasa Arab tetapi bahasa Perancis (Factbook, 2018). Bahkan, menurut Malika Rebai Mammri, bahasa Perancis terus menjadi bahasa dominan di kalangan pebisnis dan profesional dan juga bahasa Perancis masih digunakan secara luas di dalam pendidikan 
formal, penelitian, industri dan pers. Ironisnya, mereka menikmati hal tersebut (Maamri, 2009, hal. 86).

Oleh karena itu, penulis di dalam artikel ini hendak melakukan kajian tentang genealogi kajian pascakolonialisme di dalam khazanah Arab. Sebenarnya kajian yang sama sudah dilakukan. Kajian tersebut hanya mengkaji bagaimana bangsa Arab meresepsi teori pascakolonialisme di dalam khazanah pemikiran Arab. Kajian tersebut adalah penelitian Ahlam Ammari dan Samyah bin Miluud yang berjudul ad Dirasah ma Ba'da al Kuluniyah wa Talaqiha fi an Naqd al Arabi al Mu'ashir. Kajian ini hanya terbatas pada bagaimana bangsa Arab meresepsi kajian pascakolonialisme di bidang pemikiran Arab dan sama sekali tidak membahas genealogi kajian pascakolonialisme di dalam kritik sastra Arab. Kekurangan penelitian tersebut adalah bahwa kajian tersebut sama sekali tidak menyinggung bagaimana kajian pascakolonialisme di dalam karya sastra Arab. Padahal karya sastra Arab adalah salah satu manifestasi budaya Arab yang secara langsung terpengaruh oleh kolonialisme. Selain itu, di dalam penelitian tersebut, peneliti sama sekali tidak menyinggung Hasan Hanafi. Padahal Hasan Hanafi adalah tokoh yang cukup sentral di dalam kajian pascakolonial Arab dengan menawarkan konsep oksidentalisme sebagai antitesis konsep orientalisme.

Di dalam menginvestigasi genealogi kajian sastra Arab penulis menggunakan teori sastra bandingan Amerika dengan pendekatan diakronik dan metode historis. Alasan kenapa peneliti memilih teori sastra bandingan Amerika dan bukan aliran Perancis adalah fakta bahwa aliran Amerika memiliki cakupan bidang kajian yang lebih luas dan fleksibel. Aliran Amerika tidak hanya berkaitan dengan perbandingan karya sastra tetapi juga teori kritik sastra yang melingkupi lebih dari satu sastra nasional (Endraswara, 2011, hal. 90). Penggunaan pendekatan diakronik dan metode historis berfungsi agar peneliti mampu melacak pengaruh kajian pascakolonial, baik berupa penerjemahan, peminjaman, transformasi, atau adaptasi, pada kritik sastra Arab dari waktu yang berbeda mulai dari Fannon hingga saat ini.

\section{TEORI SASTRA BANDINGAN AMERIKA}

Istilah sastra banding atau bandingan muncul pertama kali di Perancis pada tahun 1816. Istilah ini berasal dari sebuah antologi pengajaran sastra yang berjudul Cours de Litterature Comparee. Di Jerman, sastra banding disebut dengan istilah vergleichende literaturgesichte yang muncul di dalam buku Moriz Carriere (1854). Sementara di Inggris istilah comparative literature diperkenalkan oleh Matthew Arnold pada tahun 1848 (Bassnett, 1995, hal. 12).

Menurut Henry Remak, salah satu perintis sastra bandingan Amerika, sastra bandingan adalah kajian yang membahas karya sastra dengan karya sastra lain di luar batas negara. Dia juga memperbolehkan penelitian sastra yang dikaitkan dengan ilmu di luar sastra, seperti seni, filsafat, sejarah, politik, ekonomi, dan agama (Remak, 1990, hal. 1). Menurut Rene Wellek, sastra bandingan sebagai studi hubungan antara dua karya sastra atau lebih telah ditafsirkan begitu luas atau disalahtafsirkan begitu banyak dan istilah tersebut telah diubah dan dikembangkan sedemikian rupa dengan sangat cepat dari awal dekade abad ke-19 hingga saat ini (Sahin, 2016, hal. 5).

Salah satu bentuk perkembangan kajian sastra bandingan adalah munculnya aliran Amerika sebagai respon aliran Perancis. Berikut adalah ruang lingkup kajian sastra bandingan menurut aliran Amerika. Pertama, kajian tentang karya sastra atau pengarangnya. Kedua, kajian tentang hubungan karya sastra dengan bidang lain seperti ilmu pengetahuan, agama, dan karya seni. Ketiga, kajian tentang teori, sejarah, dan kritik sastra antara negara yang berbeda (Endraswara, 2011, hal. 90).

Di dalam penelitian ini, penulis memilih ruang lingkup yang ketiga yaitu kajian tentang teori, sejarah dan kritik sastra dengan objek genealogi kajian sastra pascakolonialisme di dalam khazanah kritik sastra Arab. Oleh karena itu, di dalam artikel ini penulis hanya berfokus pada genealogi kajian pascakolonialisme di khazanah kritik sastra Arab dan sama sekali tidak melakukan analisis terhadap karya sastra.

Istilah genealogi berasal dari bahasa Yunani yaitu genea yang bermakna keturunan dan logos yang bermakna pengetahuan. Dari kedua kata tersebur, genealogi dapat kita maknai sebagai pengetahuan tentang keluarga 
dan penelusuran garis keturunan (Jubilee, 2010, hal. 35). Penggunaan istilah ini mengindikasikan bahwa penelitian ini hendak menginvestigasi rantai kajian pascakolonialisme di dalam khazanah sastra Arab mulai dari Fannon hingga saat ini atau sebaiknya (ke belakang) mulai saat ini sampai ke Fannon. Dengan melihat genealogi kajian pascakolonialisme, penulis berharap dapat menemukan pola rantai kajian pascakolonialisme dari awal hingga sekarang, apakah ia mengalami penerjemahan, peminjaman, transformasi, atau adaptasi.

\section{GENEALOGI KAJIAN PASCAKOLONIALISME DALAM KRITIK SASTRA ARAB}

Istilah

pascakolonialisme

(postcolonialism) pertama kali digunakan pada tahun 1959 (Cachia, 2010; O'Reilly, 2007; Hawley, 1998). Surat kabar Inggris, Daily Telegraph, menggunakan istilah postcolonialism untuk menunjuk kemerdekaan India pada tahun 1947. Pada awalnya istilah postcolonialism menunjuk pada masa setelah penjajahan Barat. Namun, seiring berkembangnya waktu istilah tersebut menjadi sebuah teori dan kajian tentang berbagai dampak kontrol kekuasaan yang bersifat kultural, ekonomi, budaya, dan historis dari penjajahan (Bill Ashcroft, 2007, hal. 168).

Perubahan makna pascakolonialisme menjadi sebuah kajian tentang dampak kontrol kekuasaan penjajah terjadi ketika Edward Said menulis sebuah buku yang berjudul Orientalism yang diterbitkan pada tahun 1978 dan kemudian berkembang menjadi teori yang disebut teori wacana kolonialis (colonialist discourse theory) seperti dalam karya para kritikus seperti Spivak dan Bhabha (Bill Ashcroft, 2007, hal. 168). Dalam kajian pascakolonialisme, Edward Said memiliki peran yang sangat vital. Dia dianggap sebagai intelektual yang telah melakukan kritik secara akademis dan sistematik tentang genetika epistemologi pengetahuan Barat tentang Timur di negara yang menjajah (Miluud, 2017, hal. 20). Edward Said membagi kekuasaan menjadi empat: kekuasaan politis (pembentukan imperialisme dan kolonialisme), kekuasaan intelektual (mendidikan timur melalui sains, linguistik, dan pengetahuan lain), kekuasaan kultural (kanonisasi selera dan teks), dan kekuasaan moral (apa yang baik dan tidak baik yang dilakukan oleh timur) (Fawaid, 2010, hal. x). Dalam bukunya tersebut, Edward Said jelas hendak menunjukkan terdapat pandangan berat sebelah mengenai bangsa Timur dan Barat yang telah diyakini oleh para intelektual Barat. Oleh karena itu, dia mencoba melakukan kajian pascakolonial, khususnya orientalisme, dalam berbagai bidang seperti politik, budaya, intelektual, dan moral. Meski begitu, penyebutan kajian pascakolonial sebagai kajian budaya dan sastra belum muncul. Penyebutan tersebut baru muncul pada tahun 80-an dan 90-an.

Edward Said memang intelektual yang memiliki peran penting di dalam kajian pascakolonial di masa-masa awal. Namun, sebenarnya sebelumnya sudah ada intelektual yang menulis buku tentang kajian pascakolonial yaitu Frantz Fanon. Dia menulis buku yang berjudul Black Skin, White Masks (1952) dan The Wretched of the Earth (1961). Dia melakukan kajian pascakolonialisme dengan berangkat dari disiplin psikologi dan menganaslisis dampak sosio-psikologis masyarakat. Dia berkesimpulan bahwa orientalisme menyebabkan alienasi dan marjinalisasi terhadap bangsa Timur. Oleh karena itu, Fanon dianggap sebagai bapak genetik teori pascakolonialisme (Miluud, 2017, hal. 25). Sebenarnya selain Fanon dan Said masih ada tokoh lain seperti Gayatri Chakravorty Spivak dengan teori subaltern dan Homi K. Bhaba dengan teori mimikri dan ambivalensi. Namun, kajian pascakolinoalisme mereka merupakan warisan atau pengaruh dari gagasan Edward Said dan Fanon.

Masuknya kajian pascakolonialisme di dalam khazanah kritik sastra Arab selalu berkaitan erat dengan penerjemahan kajian pascakolonialisme ke dalam bahasa Arab. Penerjemahan memiliki posisi yang sangat penting karena dengan adanya penerjemahan kajian sastra pascakolonialisme, gema kajian tersebut menjadi semakin mudah masuk dan diterima para kritikus dan pelajar sastra di dunia Arab. Tak dapat dipungkiri bahwa penguasaan bahasa memang selalu menjadi persoalan yang cukup signifikan dan krusial di dalam transformasi sebuah ilmu pengetahuan dari satu negara ke negara lain. Apalagi pengetahuan dan informasi pada tahun 80-an dan 90-an masih sangat terbatas dan tidak seterbuka seperti saat ini. 
Para penerjemah memang melakukan penerjemahan kajian pascakolonialisme ke dalam bahasa Arab dan tentu ini sangat membantu orang-orang Arab yang tidak menguasai bahasa asing. Perlu diketahui bahwa proses penerjemahan ini juga tidak terlepas dari persoalan ekuivalensi. Para penerjemah memiliki terjemahan yang berbeda-beda terkait istilah-istilah di dalam kajian Pascakolonialisme (postcolonialism). Ada yang menerjemah istilah postcolonialism menjadi khithab ma ba'da al isti'mar dengan alasan bahwa istilah is'ti'mar mampu menghadirkan bahasa Arab di dalam konsep kajian ilmiah dan memang tidak ada kebutuhan untuk mengimpor bahasa asing untuk menyebut istilah postcolonialism. Orang yang memperkenalkan istilah ma ba'da al isti'mar adalah Saad al Bazi'i dan Mijan ar Ruwaili di dalam buku mereka yang berjudul Dalil an Naqid al Adabi (Syamnad, 2017, hal. 186). Namun, ada penerjemah lain yang menerjemah istilah postcolonialism dengan istilah $\mathrm{ma} b a^{\prime} \mathrm{da}$ al kuluniyah dengan alasan bahwa kata tersebut adalah istilah teoritis dan baku di dalam kritik sastra yang memuat makna konsep politik, budaya dan historis yang khas (Syihab, 2013, hal. 139).

Berikut adalah beberapa penerjemahan istilah-istilah penting di dalam kajian pascakolonialisme dari bahasa asing (bahasa Inggris) ke bahasa Arab:

\begin{tabular}{|c|c|c|}
\hline No. & Bahasa Inggris & Bahasa Arab \\
\hline 1. & $\begin{array}{l}\text { Discourse } \\
\text { Representation }\end{array}$ & التمثيل الخطابي \\
\hline 2. & $\begin{array}{l}\text { Representation and } \\
\text { Orientalism }\end{array}$ & التمثيل و الاستشر اق \\
\hline 3. & $\begin{array}{l}\text { Representation and } \\
\text { Imaginative } \\
\text { Geography }\end{array}$ & التخثيل \\
\hline 4. & Ethnic Representation & التمثيل العرقي \\
\hline 5. & $\begin{array}{l}\text { Sexuality } \\
\text { Representation }\end{array}$ & التمثيل الجنسي \\
\hline 6. & Decolonization & تفكيك الاستعمار \\
\hline 7. & Hybridity & الهجنة أو التهجين \\
\hline 8. & Ambivalence & الازدو اجية \\
\hline 9. & Diaspora & الشتات \\
\hline
\end{tabular}

\begin{tabular}{llr}
\hline 10. & Mimicry & \multicolumn{1}{l}{} \\
\hline 11. & Other & \\
\hline 12. & Subaltern & آخرقهورون أوالتابع \\
\hline
\end{tabular}

Sumber: (Ar Rasis wa Al Mukhalatah, 2013)

Fakta bahwa orang Arab mengenal kajian pascakolonialisme memang tidak bisa dipungkiri. Orang Arab pertama kali mengenal kajian pascakolonialisme melalui terjemahan buku Orientalism karya Edward Said.

Syihab berkata: terjemahan dianggap sebagai sarana yang menghubungkan orang Arab dengan wacana pascakolonialisme dan buku tentang pascakolonialisme yang pertama kali diterjemah adalah buku Edward Said, Orientalism, melalui penerjemahan Kamal Abu Dib yang dianggap sebagai usaha pertama kali yang bertujuan untuk mengenalkan kritik Arab dengan metode dan pemikiran Edward Said (Syihab, 2013, hal. 132).

Seperti yang dikatakan Syihab, Orang yang pertama kali menerjemah buku Edward Said adalah Kamal Abu Dib. Setelah itu muncul berbagai usaha serius untuk melakukan penerjemahan yang tidak terbatas pada kajian pascakolonialisme tetapi juga buku-buku ilmu sosial lainnya. Menurut Sair Dib, rentang waktu proses penerjemahan buku-buku tersebut berlangsung selama sepuluh sampai tiga puluh tahun. Namun, karena itu masih masa-masa awal, proses penerjemahan masih kurang metodis dan terbatas pada usaha individu. Sair Dib menjelaskan lebih jauh lagi bahwa proses penerjemahan berlangsung tanpa adanya kesadaran dan pemahaman bahwa para terjemah telah merintis sebuah teori kritis. Karena usaha terjemah masih terbatas pada usaha individu, banyak para penerjemah yang melewatkan penerjemahan karya salah satu tokoh terpenting pascakolonialisme seperti Gayatri Spivak (Syihab, 2013, hal. 132). Oleh karena itu, hingga saat ini, jika kita hendak mencari terjemahan buku Gayatri Spivak Can The Subaltern Speaks? Maka kita tidak akan menemukan terjemahan tersebut di dalam bahasa Arab kecuali setelah 11 April 2017.

Penerjemahan memang memiliki persoalan ketidaksetaraan makna. Namun, hal ini, di sisi lain, memberi kesempatan 
penerjemah untuk menafsiri dan memahami buku yang dia terjemah, teori pascalonialisme di dalam pemahaman penerjemah. Sebagian besar buku terjemahan selalu memuat sebuah pengantar tentang gagasan yang ada di dalam buku tersebut. Pengantar tersebut ditulis oleh penerjemah dan hal ini tentu sedikit banyak akan membantu pembaca untuk memahami buku terjemahan tersebut, paling tidak menurut pemahaman penerjemah, dan mampu memperkaya proses penerimaan kajian pascakolonialisme di kalangan orang Arab (Syihab, 2013, hal. 133).

Kamal Abu Dib memiliki peran sentral di dalam penerjemahan buku-buku tentang kajian pascakolonial. Kamal Abu Dib telah menerjemah dua buku Edward Said yang berjudul Orientalism (1978) dan Culture and Imperialism (1993). Kedua buku tersebut diterjemah pada tahun 1981 dengan judul $\mathrm{Al}$ Istisyraq dan pada tahun 1997 dengan judul Ats Tsaqafah wa al Imberaliyah. Dua buku terjemahan tersebut telah membantu bangsa Arab untuk memahami konsep pascakolonialisme (orientaslisme) menurut Edward Said yang menjelaskan hubungan antara pengetahuan dan kekuasaan dan juga hubungan sastra dengan perluasan imperialisme (Syihab, 2013, hal. 133).

Setelah penerjemahan buku Orientalisme, berbagai buku terjemahan muncul karena bangsa Arab sudah mulai mengenal kajian pascakolonialisme dan mengetaui urgensi kajian tersebut. di antara buku-buku yang diterjemah adalah buku Homi K. Baba yang berjudul The Location of Culture yang diterjemah oleh Sair Dib pada tahun 2004 dengan judul Mauqi' ats Tsaqafah, buku Bill Ashcroft, Gareth Griffiths dan Helen Tiffin dengan judul The Empire Writes Back yang terbit pada tahun 1989 dan diterjemah pada tahun 2005 dengan judul Al Imbiraturiyah taridu bi al Kitabah, dan buku Ania Loomba dengan judul Colonialims/postcolonialism yang diterjemah oleh Muhammad Abdul Ghani pada tahun 2007.

Oleh karena itu, kita dapat menyimpulkan bahwa penerjemahan bukubuku asing merupakan proses pertama penerimaan bangsa Arab terhadap berbagai teori kritis seperti pascakolonialisme. Penerjemah dianggap sebagai orang yang pertama kali merespon teori pascakolonialisme bukan hanya karena semata-mata dia telah melakukan penerjemahan buku tetapi hampir disetiap semua bagian pengantar buku-buku terjemahan penerjemah selalu menyampaikan telaah tentang buku yang mereka terjemah. Dari fakta-fakta di atas, kita dapat pula menyimpulkan bahwa para penerjemah adalah kelompok masyarakat yang telah memiliki kesadaran tentang pentingnya kajian pascakolonial, Orientalism, yang memiliki berbagai karakteristik revolusi di dunia Arab (Syihab, 2013, hal. 137).

Negara Arab secara umum memang sudah merdeka. Namun, secara praktis ada beberapa negara yang saat ini masih mengalami penjajahan seperti Palestina dan Iraq. Fakta ini akhirnya memantik beberapa sastrawan Arab untuk membuat karya sastra yang berkaitan dengan kolonialisme. Di antara sastrawan yang menulis karya sastra dengan tema yang berhubungan dengan kolonialisme, sastra perlawanan (Adab al Muqawamah), seperti Mahmud Darwisy.

Selain Mahmud Darwisy yang telah menulis karya sastra dengan tema-tema penjajahan, ada beberapa sastrawan yang menulis karya sastra dengan nuansa pascakolonialisme. Di antara mereka adalah Radwi Ashur dengan karyanya Qith'ah min Auraba, Samikhah Kharis dengan karyanya Dafatir Ath Thufan, dan Abdurrahman Munif dengan karyanya Mudun al Milkh (Syamnad, 2017, hal. 191). Dengan hadirnya karya sastra yang bernuansa pascakolonial dan penerjemahan buku-buku teoripascakolonial lantas apakah kajian tentang pascakolonial menjadi ramai di dalam khazanah kritik sastra Arab.

Di dunia Arab kritik budaya dengan perspektif pascakolonialisme lebih berkembang dari pada kritik sastra dengan perspektif pascakolonialisme. Di dalam kritik budaya Arab, kita akan menemukan banyak pemikir dan intelektual yang menguasai teori pascakolonialisme dan menggunakan teori tersebut untuk mengkaji budaya Arab. Menurut pengamatan penulis, paling tidak ada dua intelektual yang representatif di dalam kajian pascakolonialisme di dunia Arab saat ini. Mereka adalah Abid al Jabiri dan Hasan Hanafi.

Abid al Jabiri melakukan kajian pascakolonialisme melalui bukunya yang berjudul Masalah al Huwwiyah al Arabiyyah wa al Islam wa al Gharb. Di dalam buku tersebut 
Abid al Jabiri mengkaji citra Arab di dalam budaya barat, hubungan oposisi biner aku dan liyan, barat dan timur, dan citra Arab dan Islam di dalam media masa barat (Jabiri, 2012, hal. 56). Sedikit berbeda dengan al Jabiri, Hasan Hanafi melakukan kajian pascakolonialisme dalam perspektif proyek tradisi dan pembaharuan. Proyek tersebut terbagi menjadi tiga, sikap orang Arab terhadap tradisi, sikap orang Arab terhadap barat, dan sikap orang Arab terhadap realitas yang mereka hadapi. Di dalam proyek yang kedua, Hasan Hanafi memunculkan konsep yang disebut oksidentalisme sebagai antitesis orientalisme barat. Berikut adalah pandangan Qamarudin Hidayat tentang oksidentalisme Hasan Hanafi:

Tujuan sederhana Oksidentalisme adalah melakukan pembebasan diri (Arab/Timur) dari pengaruh pihak lain (Barat) agar terdapat kesetaraan antara dunia Islam dan Timur pada umumnya, dan dunia Eropa dan Barat pada Umumnya (Hanafi, 2000, hal. xix).

Berbeda dengan kajian pascakolonial di bidang budaya Arab, kajian pascakolonial di bidang sastra cenderung bersifat stagnan. Kajian pascakolonial di dalam khazanah kritik sastra Arab masih sebatas pengenalan atau penerapan teori dan belum sampai pada kritik dan pengembangan teori seperti yang ada di dalam kajian budaya Arab. Di dalam kajian budaya Arab, kajian pascakolonial sudah sampai pada adaptasi teori pascakolonial terhadap persoalan yang dihadapi bangsa Arab dan juga respon kritis terhadap barat sehingga memunculkan konsep oksidentalisme. Fakta bahwa kajian pascakolonial di dalam khazanah kritik sastra Arab terbukti dari banyaknya, saat ini, kajian-kajian pascakolonial yang masih sekedar menerapkan teori-teori pascakolonial yang sudah ada sebelumnya ke dalam karya sastra Arab dan juga banyak buku-buku pengantar teori kritik sastra.

Di dalam sebuah penelitian yang berjudul Ad Dirasah Ma Ba'da Al Kuluniyah Wa Talaqqi Fi An Naqd Al Arabi Al Mua'shir, tulisan Yahya bin Walid yang berjudul Khithab ma $b a$ 'da al Isti'mar yang diterbitkan di dalam Majalah al Kalimah pada tahun 2008 dianggap menjadi salah satu kajian terpenting yang membahas pascakolonialisme. Namun, jika kita membaca tulisan tersebut maka kita akan tahu bahwa tulisan tersebut hanyalah ulasan tentang teori pascakolonialisme. Yahya bin Walid di dalam tulisannya membahas istilah pascakolonialisme, perintis kajian pascakolonialisme, pengaruh para perintis kajian kolonialsime dan akar epistemologis kajian tersebut.

Miluud berkata: Di antara kajian-kajian terpenting yang membahas istilah khithab ma ba'da al-kuluniyah adalah kajian yang dilakukan oleh Yahya bin Walid karena dia membahas secara khusus khithab ma ba'da al-kuluniyah dalam wacana kritis yang sebenarnya adalah proposisi politis yang pertama kali digunakan di dalam bidang teori politik di awal tahun tujuhpuluhan guna menjelaskan kondisi baru sebuah negara yang keluar dari cengkraman kolonialisme... (Miluud, 2017, hal. 6869).

Jika kita menelisik lebih jauh tulisan Yahya bin walid merupakan kajian tentang pascakolonialisme yang ditulis pada tahun 2008 yaitu sekitar hampir 30 tahun pasca penerbitan terjemah buku Orientalisme. Dapat kita bayangkan bahwa rentang waktu sekitar 30 tahun adalah waktu yang terlalu lama untuk sebuah buku ulasan tentang kajian pascakolonialisme. Padahal di India, sebagai perbandingan, sudah muncul beberapa teoritikus pascakolonialisme baru seperti Gayatri Chakravorty Spivak, Aruna Srivastava, Sara Suleri, dan Gauri Viswanathan.

Namun, perlu diketahui bahwa kajian pascakolonial di bidang kritik sastra paling tidak sudah sampai pada aplikasi teori kajian pascakolonial. Jika kita mencari kajian pascakolonial di dalam khazanah kritik sastra Arab tentu kita akan menemukan banyak kajian yang bersifat aplikatif. Di dalam artikel ini, paling tidak penulis akan menunjukkan dua akademisi yang cukup representatif di dalam kajian pascakolonial di dalam khazanah kritik sastra Arab. Dua orang tersebut adalah Rami Abu Shehab dan Sa'ad Bazi'i.

Rami Abu Shehab adalah pengajar di College of Art and science - Arabic departmentQatar University. Abu Shehab meraih gelar master dalam bidang sastra dan kritik Arab dari Universitas Hashemite di Yordania 2005 dan doktor dalam kritik sastra modern (wacana dan teori kritis) dari Institute of Arab Researches and Studies (Liga Arab) di Kairo pada tahun 2012. Dia bekerja di Qatar 
Foundation sebagai akademisi, kepala departemen Arab dan dosen (2005-2016). Dia saat ini bekerja sebagai dosen di Qatar University. Abu Shehab mendapatkan penghargaan Sheikh Zayed 2014 untuk bukunya Permanence and Deception. Rami melakukan penelitian dalam Sastra Dunia dan Teori Sastra. Proyek dia saat ini adalah Diaspora dan wacana pasca kolonialisme. Dia antara penelitiannya tentang kajian pascakolonialisme adalah Tada'iyat ma ba'da al isti'mar fi Riwayah A'nab Markab al 'Adzab li ath Thahir bin Jilun (2018), Fi al Mamar al Akhir Sardiyyah asy Syatat al Falastini Mandzur Ma Ba'da Kuluni (2018), dan al Kitabah Fi Azmah al Irtikhal Nahwa khithab Falastini li Asy Syatat (2018).

Sedangkan Saad al Bazi'i adalah Profesor di King Saud University di Riyadh. Dia Meraih gelar sarjana dalam Bahasa Inggris dan Sastra di King Saud University pada tahun 1974. Dia meraih gelar master dalam Sastra Inggris di University of Purdue, Indiana pada 1978, dan gelar Ph.D dalam Sastra Inggris dan Amerika di University of Purdue pada tahun 1983 dengan disertasi tentang Orientalisme dalam Sastra Eropa. Oleh karena itu, Saad al Bazi'i adalah orang yang sudah menaruh perhatian serius pada kajian pascakolonialisme semenjak di masih di bangku perkuliahan.

Dengan melihat latar belakang mereka berdua, kita dapat menyimpulkan bahwa masuk dan berkembangnya kajian pascakolonialisme di dalam khazanah kritik sastra Arab saat ini, selain melalui buku terjemah, dapat melalui para intelektual Arab yang belajar di luar negeri (Eropa atau
Amerika) dan ketika mereka kembali ke negara mereka, mereka akan mengajarkan apa yang mereka pelajari di Amerika atau Eropa kepada mahasiswa-mahasiswa Arab. Namun, ada hal yang tidak boleh kita lewatkan yaitu bahwa, saat ini, internet berperan besar di dalam transformasi kajian pascakolonialisme di dalam khazanah kritik sastra Arab sehingga meski orang Arab tidak mengenyam pendidikan di Amerika atau Eropa mereka masih bisa membaca, mempelajari, dan memahami kajian pascakolonialisme melalui internet secara bebas dan cukup terbuka, misalnya dengan mengakses berbagai buku tentang kajian pasca kolonialisme melalui situs libgen.io atau situs lainnya. Namun, meski begitu, perlu saya tegaskan lagi bahwa perkembangan kajian pascakolonialsime di dalam kritik sastra Arab masih tergolong relatif lambat dan orang Arab masih menjadi konsumen teori-teori dari Amerika atau Eropa.

\section{KESIMPULAN}

Setelah melakukan kajian tentang genealogi kajian pascakolonialisme di dalam khazanah kritik sastra Arab dari awal hingga era saat ini, penulis menyimpulkan bahwa kajian pascakolonialisme masuk ke dalam khazanah kritik sastra Arab melalui karya terjemahan, mahasiswa yang belajar di Amerika atau Eropa dan kemudian mengajar di Universitas di Arab, dan juga internet. Selain itu, sikap bangsa Arab terhadap kajian pascakolonialisme di dalam khazanah kritik sastra Arab masih sebatas sebagai konsumen dan bukan kreator.

\section{DAFTAR PUSTAKA}

Bassnett, S. (1995). Comparative Literature: A Critical Introduction. Oxford: Blackwell Publisher Ltd.

Bill Ashcroft, G. G. (2007). Post-Colonial Studies. New York: Routledge.

Cachia, P. (2010). Arabic literature: An overview. London: Routledge.

Endraswara, S. (2011). Metodologi Penelitian Sastra Bandingan. Jakarta: Bukupop.

Factbook, C. W. (2018, December 18). The World Factbook. Retrieved January 1, 2019, from CIA World Factbook Web site: https://www.cia.gov/library/publications/the-worldfactbook/geos/ag.html 
Fawaid, A. (2010). Pengantar Dari Penerjemah. In E. Said, Orientalisme (A. Fawaid, Trans., pp. vii-xiv). Yogyakarta: Pustaka Pelajar.

Hanafi, H. (2000). Oksidentalisme. (N. Buchori, Trans.) Jakarta: Penerbit Paramadina.

Hawley, J. C. (1998). The postcolonial crescent: Islam's impact on contemporary literature. New York: P. Lang.

Jabiri, M. A. (2012). Masalah al Huwwiyah al Arabiyyah wa al Islam wa al Gharb. Beirut: Markazu Dirasah al Wadah al Arabiyah.

Jubilee. (2010). Family Tree Builder. Jakarta: Elex Media komputindo.

Maamri, M. R. (2009). The Syndrome of the French Language in Algeria. International Journal of Arts and Sciences, 77 - 89.

Miluud, A. U. (2017). ad dirasah ma ba'da al kuluniyah wa Talaqqi fi an Naqd al Arabi al Mua'shir. Khemis Miliana: Djilali Bounaama University.

O'Reilly, C. (2007). Post-colonial literature. Cambridge: Cambridge Univ. Press.

Ratna, N. K. (2010). Sastra dan Cultural Studies. Yogyakarta: Pustaka Pelajar.

Remak, H. H. (1990). Comparative Literature: Its Definition and Function. In N. P. Frenz, Contemporary Literature: Method and Perspective. Illinois: Southere Illinois University Press.

Sahin, E. (2016). On Comparative Literature. International Journal of Literature and Arts, 5-12.

Syamnad. (2017). Khitab Ma Ba'da al Isti'mar fi an Naqd al Adabi. Al Mi'yar, 185-199.

Syihab, R. A. (2013). Ar Rasis wa Al Mukhalatah. Beirut: Al Muassasah al Arbiyah li ad Dirasah wa an Nasr. 